\title{
Comparison of Intercalated and Exfoliated Montmorillonite/Amidoximated Polyacrylonitrile: Preparation, Characterization and Adsorption Capacity of Uranyl
}

\author{
Weiping $\mathrm{Li}^{1,2, a}$, Xiaoyuan $\mathrm{Han}^{2, \mathrm{~b}}$, Xiaoyun Wang ${ }^{1, \mathrm{c}}$, Ruirong Zhang ${ }^{2, \mathrm{~d}}$, Xiufang \\ Zhai $^{2, e}$, Yu Wang ${ }^{2, \mathrm{f}}$, Hui Xu ${ }^{2, \mathrm{~g}}$, and Hongxia Zhang ${ }^{1, \mathrm{~h},{ }^{*}}$ \\ ${ }^{1}$ School of Nuclear Science and Technology, Lanzhou University, Lanzhou 730000, China; \\ ${ }^{2}$ Northwest Institute of Nuclear Technology, Xi'an 710024, China \\ ayuanfangad@163.com, ${ }^{\text {b2 } 2786884743 @ q q . c o m, ~ c 447314004 @ q q . c o m, ~ d 517130336 @ q q . c o m, ~}$ \\ e363853455@qq.com, ${ }^{\mathrm{f}} 35307488 @ q q . c o m,{ }^{9} x i a o b b i e @ 163 . c o m, ~{ }^{\mathrm{h}} \mathrm{hxzhang@lzu.edu.cn}$
}

Keywords: Amidoxime; intercalation; exfoliation; uranyl; montmorillonite.

\begin{abstract}
Intercalated and exfoliated montmorillonite/amidoximated polyacrylonitrile (IAPAN/Mont and EAPAN/Mont) were prepared by using in situ polymerization technique. Intercalated Mont/APAN was obtained through polymerization with organ-montmorillonite and acrylonitrile. However, it became exfoliated when using Na-montmorillonite as a reactant. XRD, FT-IR, and CHN analysis were performed and the results showed the successful synthesis of the two materials. Adsorption of uranyl by using the new prepared materials was also conducted. The results showed that excellent adsorption capacity of $634 \mathrm{mg} / \mathrm{g}$ and $543 \mathrm{mg} / \mathrm{g}$ at $27^{\circ} \mathrm{C}$ using IAPAN/Mont and EAPAN/Mont respectively, were obtained.
\end{abstract}

\section{Introduction}

Nuclear power, as a major and promising approach to solve the energy problem, becomes more and more attractive since 1950s.However, the treatment of wastewater containing uranium generated in the operation of the nuclear plant, grows to be an important problem one should meet[1].Therefore, the study about removal or recovery of uranium from wastewater was performed extensively in the recent years.

The recovery of uranium involves various techniques such as precipitation[1], extraction[2], ion exchange[3] and adsorption[4 6].Because of the low cost and convenience of operation, adsorption by inorganic and organic adsorbent gains an increasing concern in comparison of the other techniques. Compared to inorganic adsorbent, organic adsorbent is more superior resulting from the high selectivity and adsorption capacity. Among the organic adsorbents, amidoxime functioned material exhibits excellent adsorption properties and may be the most promising material for the recovery of uranium, wherever from seawater or wastewater.

Amidoxime functioned material contains amidoxime and amino in the reactive groups, and can form chelate with uranyl or tricarbonate uranyl, which dominate in the acid solution and weak basic solution respectively. In order to enhance the hydrophilicity as well as the adsorption capacity, inorganic clay mineral like montmorillonite or $\mathrm{SiO} 2$ were attempted to incorporate into the material. For montmorillonite, two methods, named intercalated and exfoliated polymerization were usually used to prepare the composite material. However, there is no direct comparison of the two synthesis material in the literatures, to our best knowledge. This paper described the difference of intercalated and exfoliated APAN/Mont, involving the synthesis process, the characteristic and the adsorption capacity towards uranium. 


\section{Experimental}

Materials. Na-montmorillonite(Na-Mont) with a purity of $98 \%$ was purchased from Nanocor Inc and used for preparation of Mont/APAN. Cetyltrimethylammonium bromide(CTAB)was obtained from Shanghai Boao Bio-Technology Co., Ltd, China. Acrylonitrile was purchased from Shanghai Lingfeng Chemical Reagent Co., Ltd and purified by vacuum distillation to remove the dissolvent and enable the polymerization. Ammonium persulfate was obtained from SCRC, China, and used as an initiator of polymerization. Hydroxylamine hydrochloride for the formation of amidoxime was also purchased from SCRC. Milli-Q water $(>18 \mathrm{M} \Omega$ ) was used in the synthesis and adsorption process. Uranyl, which was prepared in the form of uranyl nitrate, was diluted to the concentration of $0.27 \mathrm{mmol} / \mathrm{L}$ and used for the adsorption experiments. All chemicals were of analytical grade unless stated otherwise.

Synthesis of EAPAN/Mont. Exfoliated montmorillonite/amidoxime polyacrylonitrile (EAPAN/ Mont) was prepared using in-situ emulsion polymerization technique refer to the literature[7]. 4g Na-Mont and $350 \mathrm{~mL}$ deionized water were mixed, and the mixture was shaking for $2 \mathrm{~h}$ to enable the dispersion of montmorillonite. Then $25 \mathrm{~mL}$ of purified acrylonitrile was poured into the mixture and transferred into a three-neck bottle equipped with a thermometer, a reflux condenser and a stirrer. After the temperature became $50^{\circ} \mathrm{C}$, the initiator,ammonium persulfate solution was added into the mixture drop by drop to enable the polymerization. The temperature was raised and remained at $70^{\circ} \mathrm{C}$ for 3h. After that, filtration, drying and grinding of the polymer were performed and used for the amidoximation.3g of the polymer was taken and mixed with $100 \mathrm{~mL}$ deionized water, $12 \mathrm{~g}$ hydroxylamine hydrochloride and 50mL methanol. The mixture was adjusted to $\mathrm{pH} 7$ and the reaction was enabled at $70^{\circ} \mathrm{C}$ for $2 \mathrm{~h}$, then EAPAN/Mont was obtained.

Synthesis of IAPAN/Mont. Intercalated montmorillonite/amidoxime polyacrylonitrile(IAPAN/ Mont) was prepared by using the similar technique as EAPAN/Mont. The difference was that the first organ-montmorillonite was prepared using the following procedure, and used for the polymerization.4g Na-montmorillonite, dispersed in 350mL deionized water, was mixed with $5 \mathrm{~g}$ $\mathrm{CTAB}$ and enable the reaction at room temperature under continuous stirring for $2 \mathrm{~h}$, then filtrated until the filtrate has no bromide ion. The rest of the synthesis process refers to the preparation of EAPAN/Mont.

Characterization. XRD pattern was recorded in X'Pert Pro X-ray powder diffractometer in the wide angle mode to confirm the intercalation or exfoliation of the layers of montmorillonite. NEXUS 670 Fourier Transform Infrared Spectrometer was used to obtain FT-IR spectra and confirm the formation of amidoxime. $\mathrm{CHN}$ analysis, which can provide information of $\mathrm{N}$ content of the polymer and enable the calculation of amidoxime content, was also performed. The determination of uranyl was conduct using UV-vis spectroradiometer with Arsenazo(III) as a complexant.

Batch experiment. Batch experiments were employed to assess the adsorption property of IAPAN/Mont and EAPAN/Mont for uranyl. The adsorption capacity for uranyl was calculated using the following equation, where $C_{i}$ is the initial and $C_{f}$ is the final concentration of uranyl in the solution.

$$
\% \text { Sorption }=\frac{C_{f}-C_{i}}{C_{f}} \times 100
$$

\section{Result and discussion}

Characterization. To confirm the structure of montmorillonite after polymerization, X-ray diffraction spectra of IMont/PAN and EMont/PAN were shown in Fig.1a.The XRD patterns of Na-Mont matched well with the literature[6,24].The characteristic peak of $\mathrm{d}_{001}$ at $2 \theta=7.1$ moved to 4.6, which reflected an increase of the distance between the sheets of Na-Mont after the incorporation of $\mathrm{CTAB}$, corresponding to a basal spacing of $1.24 \mathrm{~nm}$ to $1.91 \mathrm{~nm}$. After polymerization, IAPAN/Mont showed similar peak expect a little shift of the position, suggesting an intercalated structure of the montmorillonite. However, the disappear of $d_{001}$ peak for EMont/PAN indicated that 
the ordered sheets structure of montmorillonite was completely destroyed and exfoliated EMont/PAN was successful prepared. There is no doubt that amidoximation have no influence on the structure of the layers of montmorillonite, so XRD pattern of IAPAN/Mont and EAPAN/Mont were not shown here.

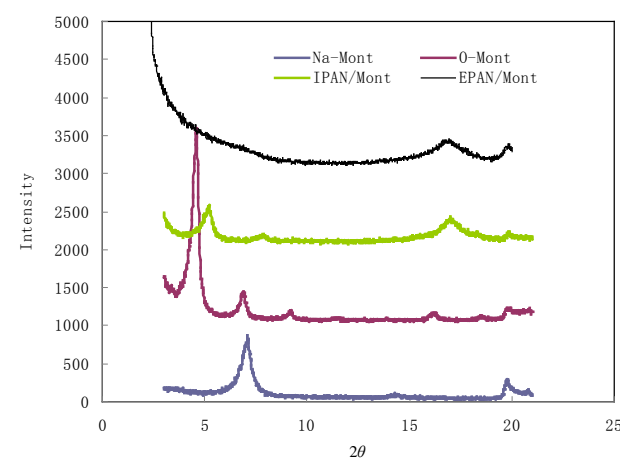

(a)

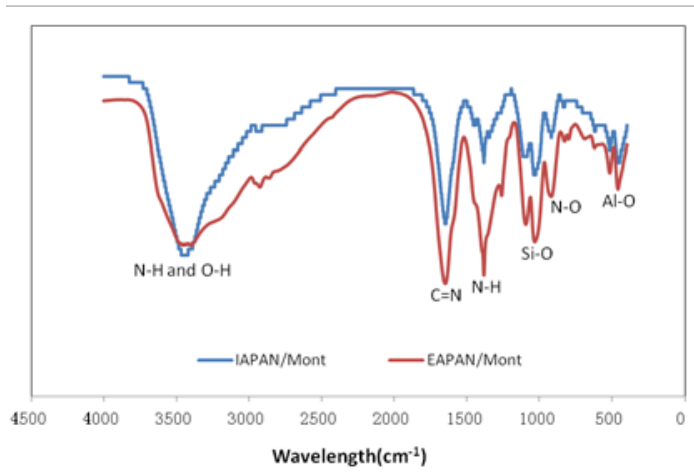

(b)

Fig.1 (a)The XRD patterns of Na-Mont, O-Mont, IPAN/Mont and EPAN/Mont (b)The FT-IR spectra of IAPAN/Mont and EAPAN/Mont

Fig.1b shows the FT-IR spectra of IAPAN/Mont and EAPAN/Mont. It can be seen from Fig.1b that the basic characteristic peaks are at $3000 \sim 3800 \mathrm{~cm}^{-1}$ for $\mathrm{O}-\mathrm{H}, 523$ and $464 \mathrm{~cm}^{-1}$ for Al-O bonds, $1034 \mathrm{~cm}^{-1}$ for Si-O-Si bonds, which corresponded to the Na-Mont[3], confirmed the existence of the montmorillonite. The sharp peak was at $1650 \mathrm{~cm}^{-1}$ referring to $\mathrm{C}=\mathrm{N}, 1384 \mathrm{~cm}^{-1}$ to $\mathrm{N}-\mathrm{H}$ and 912 $\mathrm{cm}^{-1}$ to N-O representing the successful conversion of AN to AO. There is no significant difference between IAPAN/Mont and EAPAN/Mont, indicating the similarity of the two materials.

In order to calculate the AN content contained in the material, $\mathrm{N}$ content was determined using CHN analyzer. $\mathrm{N}$ content in the IAPAN/Mont and EAPAN/Mont were $22.19 \%$ and $24.18 \%$ respectively, from which the conversion fraction of AN to AO were calculated to be $88.9 \%$ and 93.6\%.This may be attributed to the long-chain CTAB, which incorporated into the layers of montmorillonite, and block the smaller acrylonitrile molecule to get into the layers, and then the polymerized PAN surrounds montmorillonite, facilitating the conversion of AN to AO.

Adsorption of uranyl on IAPAN/Mont and EAPAN/Mont. Adsorption experiments were conduct to compare the adsorption capacity of IAPAN/Mont and EAPAN/Mont. From Fig.2a we can see that the adsorption capacity of IAPAN/Mont was superior to EAPAN/Mont, which corresponds to the AO content calculated from the $\mathrm{N}$ content. Langmuir isotherm equation was used to model the adsorption behavior of the two materials, and the results showed that they both matched Langmiur model very well( $\mathrm{R}^{2}$ were 0.9942 and 0.9922$)$. The adsorption capacity of the materials was calculated to be $543 \mathrm{mg} / \mathrm{g}$ and $634 \mathrm{mg} / \mathrm{g}$ at $27^{\circ} \mathrm{C}$ for EAPAN/Mont and IAPAN/Mont respectively.

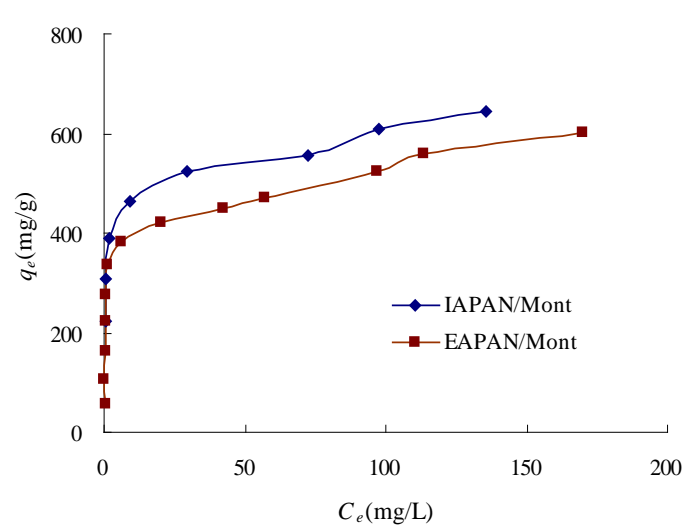

(a)

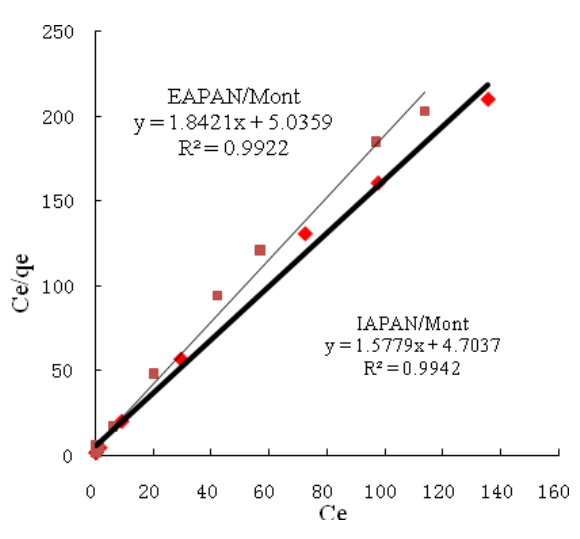

(b)

Fig.2 Adsorption isotherm(a) and Langmiur modeling (b) for adsorption of uranyl on IAPAN/Mont and EAPAN/Mont 


\section{Conclusion}

Comparison of IAPAN/Mont and EAPAN/Mont shows significant difference in the structure of montmorillonite layers, $\mathrm{N}$ content and the adsorption capacity. IAPAN/Mont seems to be superior to EAPAN/Mont in the adsorption of uranyl, resulting from the higher conversion percentage of AN to $\mathrm{AO}$, which can be used to recover or remove uranium from wastewater or other industrial effluent containing uranium.

\section{Acknowledgements}

National Natural Science Foundation of China (No.21101083, J1030962) and Foundation research Funds for Central University [lzujbky-2013-191] are gratefully acknowledged.

\section{References}

[1] J. Kim, C. Tsouris, Richard T.Recovery of Uranium from Seawater: A Review of Current Status and Future Research Needs, Separ Sci Technol. 48 (2013).

[2] Riordan, C, Bustard, M,Putt, R. Removal of uranium from solution using residual brewery yeast: Combined biosorption and precipitation, Biotechnol Lett.19 (1997), 385-387.

[3] Kim, KW; Lee, EH; Shen, YJ.Removal of Residual Uranium in Simulated Radwaste Solution By TBP Extraction, Separ Sci Technol. 30 (1995), 3351-3362.

[4] Tavakoli H, Sepehrian H, Semnani.F.Recovery of uranium from UCF liquid waste by anion exchange resin CG-400: Breakthrough curves, elution behavior and modeling studies. Ann Nucl Energy. 54 (2013), 149-153

[5] S.Korichia, A.Bensmailia. Sorption of uranium (VI) on homoionic sodium smectite experimental study and surface complexation modeling. J.Hazard.Mater.169 (2009), 780-793.

[6] Y.Liu, X.Cao, R.Hua,et al.Selective adsorption of uranyl ion on ion-imprinted chitosan/PVA cross-linked hydrogel. Hydrometallurgy.104 (2010), 150-155.

[7] T.Tsuruta.Removal and Recovery of Uranyl Ion Using Various Microorganisms.J. Biosci Bioeng. 94 (2002), 23-28.

[8] J. Shen, J. Yu, Y. Chu, et al. Preparation and uranium sorption performance of amidoximated polyacrylonitrile/organomontmorillonite composite. Advanced Materials Research.476-478 (2012), 2317-2322. 